\title{
Evaluation of Visual Outcome in Proliferative Diabetic Retinopathy after Panretinal Photocoagulation
}

\author{
R.M.A. Sujatha ${ }^{1}$, S. Samreen ${ }^{2}$ \\ ${ }^{1}$ Department of Ophthalmology, Dr. B. R. Ambedkar Medical College, Bengaluru, Karnataka, India. \\ ${ }^{2}$ Department of Ophthalmology, Dr. B. R. Ambedkar Medical College, Bengaluru, Karnataka, India.
}

\section{ABSTRACT}

\section{BACKGROUND}

Several studies have reported on the visual outcome of panretinal photocoagulation (PRP). Early photocoagulation reduces the risk of severe visual loss, progression of retinopathy and the need for vitrectomy. Though vision is maintained, there are causes such as cystoid macular oedema and vitreous haemorrhage which can lead to diminished vision even after PRP. We wanted to evaluate the maintenance of existing vision after PRP for proliferative diabetic retinopathy (PDR) and assess the causes of severe visual loss after PRP.

\section{METHODS}

28 patients with PDR attending the retina clinic who fit the high risk criteria provided by ETDRS were included in this study. After assessment of visual acuity, intraocular tension, fundus examination with direct and indirect ophthalmoscopy, +90D lens, fundus fluorescein angiography (FFA), patients were treated with PRP. After PRP visual acuity testing, and retinal examination was done after 1 month, 3 months, 6 months and 1 year.

\section{RESULTS}

At baseline $30 \%$ eyes had visual acuity of $6 / 6-6 / 9,44 \%$ had visual acuity of $6 / 12$ $6 / 36$ and $26 \%$ eyes had visual acuity of $<6 / 60.73 .3 \%$ of patients with visual acuity of $6 / 6-6 / 9$ at baseline retained their vision, $26.67 \%$ had decreased vision. $86.36 \%$ of patients with visual acuity $6 / 12-6 / 36$ at baseline retained their vision, $9.09 \%$ had decreased vision and in $4.55 \%$ vision improved. $92.30 \%$ with poor baseline visual acuity $(\leq 6 / 60)$ retained the same visual acuity and $7.69 \%$ of them improved to $6 / 9$ at the end of 1 year. Causes of visual loss following PRP at the end of 1 year included vitreous haemorrhage (33.33\%), pre-retinal haemorrhage $(33.33 \%)$, epiretinal membrane (33.33\%), tractional retinal detachment (8.33\%), macular oedema (8\%), choroidal effusion (8\%), and acceleration of pre-retinal fibrosis (8\%).

\section{CONCLUSIONS}

After PRP visual acuity was maintained at baseline in majority of patients. However, diminution of vision can occur due to vitreous haemorrhage, pre-retinal haemorrhage and macular oedema.

\section{KEY WORDS}

Proliferative Diabetic Retinopathy (PDR), Panretinal Photocoagulation (PRP)
Corresponding Author:

Dr. Shaeeza Samreen

No. 27, Berlie Street,

Langford Town, Shantinagar,

Bangalore-560025, Karnataka, India.

E-mail: shaeezas@gmail.com

DOI: $10.14260 / j e m d s / 2019 / 716$

Financial or Other Competing Interests: None.

How to Cite This Article:

Sujatha RMA, Samreen S. Evaluation of visual outcome in proliferative diabetic retinopathy after panretinal photocoagulation. J. Evolution Med. Dent. Sci. 2019;8(44):3297-3301, DOI: $10.14260 /$ jemds/2019/716

Submission 02-08-2019,

Peer Review 15-10-2019,

Acceptance 22-10-2019,

Published 04-11-2019.

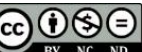




\section{BACKGROUND}

Diabetic retinopathy remains a leading cause of visual disability in the developed world. At present diabetic retinopathy is projected to become a significant cause of blindness in the coming decade even in the developing countries. In India it is estimated that the number of diabetics will rise from 19 million to 57 million between 1995 and 2025. Diabetic retinopathy is the leading cause for microvascular complications, among them vision impairment. Several studies indicate that $23 \%$ to $36 \%$ of all diabetics irrespective of the duration of the diabetes will develop diabetic retinopathy. Panretinal photocoagulation reduces the risk of developing visual loss from the complications of proliferative diabetic retinopathy. In spite of the general effect of this treatment, some patients develop visual loss either when the treatment is started too late or it is insufficient.

Photocoagulation still remains the most effective treatment for proliferative diabetic retinopathy. ${ }^{1}$ The beneficial effects of panretinal photocoagulation for diabetic retinopathy and its effectiveness in decreasing the incidence of blindness were established almost 20 years ago by Diabetic Retinopathy Study (DRS). ${ }^{2}$ Both (DRS) and Early Treatment Diabetic Retinopathy Study (ETDRS) provided data to establish the guidelines for detection and effective treatment of proliferative diabetic retinopathy (PDR) and diabetic macular oedema. The DRS demonstrated that PRP reduces the risk of severe visual loss in high risk PDR by $50-60 \%$. Harmful effects of the treatment were also identified and were somewhat greater in the xenon treated group of the DRS. Estimates of persistent visual loss attributable to treatment in the xenon treated eyes were $19 \%$ with loss of 1 line of visual acuity and $11 \%$ with loss of 2 lines. In the argon treated group, these numbers were $11 \%$ and $3 \%$ respectively. There was complete regression of NVD in $29.8 \%$ and partial regression in $24.5 \%$ of eyes 12 months after treatment. GW Blankenship ${ }^{3}$ in his study noted during a one month follow up that six eyes had visual acuity of $6 / 60$ or less. Three eyes with central laser photocoagulation and one eye with peripheral PRP of retina had increased macular swelling; and the remaining eye of each group had increased vitreous haemorrhage as a cause for decreased acuity. Vander JF, Duker JS, Benson WE, Brown GC, McNamara JA, Rosenstien $\mathrm{RB}^{4}$ in their study noted that $59 \%$ had regression of high-risk retinopathy characteristics within 3 months of treatment. $52 \%$ had a final visual acuity of 20/20 after 4 years of follow up. $37 \%$ sustained a delayed vitreous haemorrhage. Therefore, it was concluded that the beneficial effect of panretinal photocoagulation on visual outcome is related to the regression of risk factors and long-term visual prognosis in high-risk eyes after PRP is excellent. A study conducted by H. Richard McDonald and Howard Schatz ${ }^{5}$ showed that most common cause of decreased visual acuity was chronic macular oedema that had developed following laser treatment, occurring in 14 (8\%) eyes. 99 eyes (53\%) had pre laser visual acuity $20 / 40$ or better, 48 eyes (28\%) has visual acuity between $20 / 50$ and $20 / 100,34$ eyes (19\%) had $20 / 200$ vision or worse.

We wanted to evaluate the maintenance of existing vision after panretinal photocoagulation for proliferative diabetic retinopathy (PDR) patients and assess the causes of severe visual loss after panretinal photocoagulation (PRP).

\section{METHODS}

This is an interventional study conducted between January 2017 to December 2017 at Dr. B. R. Ambedkar Medical College and Hospital, Bengaluru. During the above mentioned period 50 randomly selected cases diagnosed with proliferative diabetic retinopathy attending retinal clinic were included for the study. The statistical study was done by using descriptive epidemiology using proportions and sample size calculated using StatCalc. 50 eyes of 28 patients fulfilling the selection criteria were included in the study after their informed written consent.

\section{Inclusion Criteria}

1. Age 18 years and above.

2. Patients diagnosed with proliferative diabetic retinopathy with following high risk characteristics were included:

- Neovascularization at the disc involving more than $1 / 3$ to $1 / 2$ disc area.

\section{Or}

- Neovascularization at the disc and vitreous or preretinal haemorrhage.

\section{Or}

- Neovascularization elsewhere involving more than $1 / 2$ disc area and pre-retinal or vitreous haemorrhage.(6)

\section{Exclusion Criteria}

1. Patients with mild or moderate Non proliferative diabetic retinopathy.

2. Patients with Pre-proliferative diabetic retinopathy.

3. Major ocular surgery within past 6 months.

4. Patients for whom Panretinal photocoagulation was done within past 6 months.

Data was collected from patients' records including the patients' age, gender, and duration of diabetes mellitus, presence or absence of hypertension; whether patient is on insulin or oral hypoglycaemic agents, presence of other systemic diabetic complications and other general illnesses.

\section{Pre Laser Evaluation}

Ocular parameters to be assessed include best-corrected visual acuity using Snellen's visual acuity chart, intraocular pressure using Goldman applanation tonometer, slit lamp examination and retinal examination using direct ophthalmoscopy, indirect ophthalmoscopy and slit lamp biomicroscopy with +90D lens. Fundus fluorescein angiography was done in all cases before laser therapy.

\section{Procedure of Panretinal Photocoagulation}

PRP was done using topical anaesthesia for patients who fit into the high risk characteristic criteria according to guidelines provided by ETDRS. A complete panretinal photocoagulation was performed with Iridex Green Laser, doubled frequency laser with wavelength $532 \mathrm{~nm}$. 


\section{Lens Used}

Mainster PRP lens

\section{Laser Parameters}

1. Total number of Burns: $1600-2000$.

2. Spot Size: $200 \mu$.

3. Power: 200-400 mw.

4. Duration: $200 \mathrm{msec}$.

\section{Sequence of Application of Laser Burns}

1. Close to the disc; below the inferior temporal arcades.

2. Protective barrier around the macula to prevent inadvertent treatment of the fovea; above the superotemporal arcade.

3. Nasal to the disc; completion of the posterior pole treatment

4. Peripheral treatment until completion.

This procedure was done in 2 to 3 sittings. At follow up of $1^{\text {st }}$ month $3^{\text {rd }}$ month, $6^{\text {th }}$ month and 1 year visual acuity and detailed retinal examination (Using indirect ophthalmoscopy) was done and any problems recorded. Slit lamp examination with +78D/90D lens was done to examine the macula. Fundus photography was done in selected cases. For those with persisting lesions fundus fluorescein angiography was repeated and additional (Fill in) panretinal photocoagulation was done.

Visual acuity was defined 'stable' when vision at baseline was maintained after PRP; 'decreased' when the baseline vision decreased by 2 lines and 'improved' when the baseline vision improved by 2 lines after PRP at the end of one year. Poor visual acuity was defined as a corrected visual acuity less than $6 / 60$ on the Snellen's chart in the eye that received panretinal photocoagulation.

\section{Statistical Analysis}

In this study visual outcome after panretinal photocoagulation was evaluated. Percentage of patients in whom baseline was maintained was noted. For those patients with decreased vision after PRP, the causes for decreased vision were analyzed. The statistical analysis was done using descriptive epidemiological methods using pie charts, bar diagrams.

\section{RESULTS}

This is a prospective study to evaluate visual outcome after panretinal photocoagulation for PDR at Dr. B. R. Ambedkar medical college and hospital, Bengaluru. Patients were followed up at 1 month, 3 months, 6 months and 1 year after laser treatment. A total of 50 eyes of 28 patients received PRP during the study period. Among the 28 patients 21 had bilateral PDR at baseline. In our study of 50 eyes, $90 \%$ were males and $5 \%$ were females. Out of the 50 eyes there were 8 cases in the 40 - 50 age group, 23 cases in the 51-60 age group, 13 in the 61-70 age group and 6 were above $>70$ years.
All the patients were examined for a period of 1 year at 1 month, 3 months, 6 months and 1 year post PRP. Visual acuity was recorded, detailed fundus examination was done and complications which caused decreased visual acuity were evaluated. In our study $74.3 \%$ retained their baseline vision and decreased vision was noted in $22 \%$ of patients. Our study co-relates well with the studies done by others.

1. Relationship between duration of diabetes and post PRP vision at the end of 1 year: The average duration of diabetes of patients in our study was 11.06 years. With $<10$ years of diabetes $76 \%$ subjects retained the same vision, $20 \%$ of eyes had decreased vision. In patients with 10-20 years of diabetes $73 \%$ of patients had retained same vision, and $30.4 \%$ had decreased vision. This indicated that there is significant association of post PRP visual acuity with duration of diabetes. This is consistent with the guidelines shown in the ETDRS that when PRP is initiated early, visual prognosis is better.

\begin{tabular}{|c|c|c|c|}
\hline $\begin{array}{c}\text { Duration of } \\
\text { Diabetes }\end{array}$ & $\begin{array}{c}\text { No. of Eyes with } \\
\text { Vision Maintained }\end{array}$ & $\begin{array}{c}\text { No. of Eyes with } \\
\text { Vision Improved }\end{array}$ & $\begin{array}{c}\text { No. of Eyes with } \\
\text { Vision Decreased }\end{array}$ \\
\hline$<10$ years & 19 & 01 & 05 \\
\hline $10-\leq 20$ years & 17 & 0 & 07 \\
\hline$>20$ years & 02 & 0 & 0 \\
\hline \multicolumn{3}{|c|}{ Table 1. Distribution of Eyes Based on Duration of Diabetes } \\
and Vision at 1 Year Post PRP \\
\hline
\end{tabular}

2. Visual acuity before laser: At baseline $30 \%$ eyes had visual acuity of $6 / 6-6 / 9,44 \%$ had visual acuity of $6 / 12-6 / 36$ and $26 \%$ eyes had visual acuity of $<6 / 60$.

\begin{tabular}{|c|c|c|}
\hline Baseline Vision & No. of Eyes & Percentage \\
\hline $6 / 6-6 / 9$ & 15 & $30 \%$ \\
\hline $6 / 12-6 / 36$ & 22 & $44 \%$ \\
\hline$<6 / 60$ & 13 & $26 \%$ \\
\hline \multicolumn{2}{|c|}{ Table 2. Visual Acuity Before Laser } \\
\hline
\end{tabular}

\begin{tabular}{|c|c|c|c|}
\hline \multicolumn{4}{|c|}{ No.(\%) of Eyes } \\
\hline $\begin{array}{c}\text { Visual } \\
\text { Acuity }\end{array}$ & $\begin{array}{c}\text { No.(\%) of Eyes at } \\
\mathbf{1}^{\text {st }} \text { Month }\end{array}$ & $\begin{array}{c}\text { No.(\%) of Eyes at } \\
3^{\text {rd }} \text { Month }\end{array}$ & $\begin{array}{c}\text { No.(\%) of Eyes at } \\
\mathbf{6}^{\text {th }} \text { Month }\end{array}$ \\
\hline $6 / 6-6 / 9$ & $12(24 \%)$ & $10(20 \%)$ & $13(26 \%)$ \\
\hline $6 / 12-6 / 36$ & $22(44 \%)$ & $25(50 \%)$ & $22(44 \%)$ \\
\hline$\leq 6 / 60$ & $16(32 \%)$ & $15(30 \%)$ & $15(30 \%)$ \\
\hline \multicolumn{4}{|c|}{ Table 3. Visual Acuity at 1, 3, 6 Months Post PRP } \\
\hline
\end{tabular}

3. Visual acuity after laser at $1^{\text {st }}$ month, $3^{\text {rd }}$ month and $6^{\text {th }}$ month post PRP, according to paired $t$-test.

4. Visual acuity at 1-year post PRP $73.3 \%$ of patients with visual acuity of 6/6- 6/9 at baseline retained their vision, $26.67 \%$ had decreased vision. $86.36 \%$ of patients with visual acuity $6 / 12-6 / 36$ at baseline retained their vision, $9.09 \%$ had decreased vision and $4.55 \%$ vision improved. $92.30 \%$ with poor baseline visual acuity $(\leq 6 / 60)$ at baseline retained had the same visual acuity and $7.69 \%$ of them improved to $6 / 96 / 12-6 / 36$ at the end of 1 year, according to paired $t-$ test.

\begin{tabular}{|c|c|c|c|}
\hline Baseline & \multicolumn{3}{|c|}{ Visual Acuity at 1 Year Post PRP } \\
\hline & $6 / 6-6 / 9$ & $6 / 12-6 / 36$ & $\leq 6 / 60$ \\
\hline $6 / 6-6 / 9$ & $73.30 \%$ & $26.67 \%$ & \\
\hline $6 / 12-6 / 36$ & $4.55 \%$ & $86.36 \%$ & $9.09 \%$ \\
\hline$\leq 6 / 60$ & & $7.69 \%$ & $92.30 \%$ \\
\hline \multicolumn{3}{|c|}{ Table 4. Visual Acuity at 1 Year Post PRP } \\
\hline
\end{tabular}




\section{DISCUSSION}

Analyses of visual change after photocoagulation therapy in a retrospective study by Murat Dogru et al (7) had done in 1998 revealed that $73 \%$ of the eyes with early PDR had stable vision or improvement by $\geq 2$ lines at the end of 10 year follow up visit. The figures were $62 \%$ and $52 \%$ for eyes with advanced and end stage PDR respectively. In a study, Qian Z et $\mathrm{al}^{(8)}$ proved that PRP was effective in 122 eyes $(85.31 \%)$ out of 143 eyes. Visual acuity improved in 32 eyes (23.38\%), vision was maintained in 87 eyes (60.84\%) and there was a decrease in 24 eyes (16.78\%). In a study by Richard S. Kaiser et al ${ }^{9} 96 \%$ of eyes with poor visual acuity $(\leq 20 / 200)$ at baseline still had poor visual acuity at 1 year and $76 \%$ with good visual acuity $(\geq 20 / 40)$ at baseline maintained good visual acuity at one year. Little reported that $60 \%$ of the 66 cases in his series treated with PRP had 20/30 or better and $75 \%$ had $20 / 100$ or better visual acuity at the 12 year follow up visits. Likewise, the visual acuity results from the Bascom Palmer Diabetic Retinopathy Study at 15 years were similar to those at 10 years with $58 \%$ of the eyes attaining $20 / 40$ or better vision and $5 \%$ of the eyes had $20 / 200$ or worse visual acuity.

\begin{tabular}{|c|c|c|c|c|c|}
\hline $\begin{array}{c}\text { Visual Status at 1 } \\
\text { Year Post PRP }\end{array}$ & \multicolumn{5}{|c|}{ No. (\%) of Eyes } \\
\hline & $\begin{array}{c}\text { Our } \\
\text { Study }\end{array}$ & $\begin{array}{c}\text { Richard } \\
\text { Kaiser } \\
\text { et al }\end{array}$ & $\begin{array}{c}\text { Reema } \\
\text { Mohan } \\
\text { et al }\end{array}$ & $\begin{array}{c}\text { Dogru } \\
\text { M } \\
\text { et al }\end{array}$ & $\begin{array}{c}\text { Qian Z } \\
\text { et al }\end{array}$ \\
\hline vision maintained & $37(74 \%)$ & $143(76 \%)$ & $140(73.2 \%)$ & $28(73 \%)$ & $87(60.84 \%)$ \\
\hline $\begin{array}{c}\text { Percentage of eyes } \\
\text { whose vision decreased }\end{array}$ & $11(22 \%)$ & & $27(14.3 \%)$ & $10(27 \%)$ & $24(16.78 \%)$ \\
\hline $\begin{array}{c}\text { Percentage of eyes whose } \\
\text { vision improved }\end{array}$ & $2(4 \%)$ & & $11(5.74 \%)$ & & $32(23.38 \%)$ \\
\hline Table 5. Comparison of Studies of Visual Status at 1 Year Post PRP \\
\hline
\end{tabular}

\section{Causes of Visual Loss at the End of One Year Post PRP}

In our study vitreous haemorrhage was the most common cause of visual loss followed by preretinal haemorrhage, macular oedema, choroidal effusion, tractional retinal detachment, epiretinal membrane and choroidal effusion. Recurrence of retinal neovascularization was not identified in any of the patients. Late post laser haemorrhage indicates incomplete regression of neovascularization. Among the 4 patients who had vitreous haemorrhage, 1 patient underwent vitrectomy. Following surgery his vision improved to 6/9. 2 patients developed macular oedema following PRP. This persistent macular oedema developed as a side effect of PRP. Tractional retinal detachment involving the macula caused a drop in the vision of 3 lines. Epiretinal membrane (ERM) which developed following PRP caused visual loss of 4 lines in 1 eye. The forces of vitreoretinal traction could have produced tangential traction on the retinal surface, causing visual loss if the macula is involved. Whether or not photocoagulation promotes formation of ERM is unknown. Laser treatment however stimulates contraction of membrane, increases macular surface wrinkling and reduces vision. Choroidal effusion developed in one patient and this could be because large numbers of burns were placed in one session

A study done by Rema Mohan et al(10) showed that causes of visual loss included vitreous haemorrhage in 20 subjects (31.\&\%), progression of cataract in 19 (30\%), chronic macular oedema in 15 eyes (23.8\%), pre retinal haemorrhage in the macula in $6(9.5 \%)$ of case and pre retinal fibrosis in the macula in 3 subjects(4.7\%). In a study by Richard $\mathrm{H}$ et al, the most common cause of decreased vision was chronic macular oedema that had developed following laser treatment, occurring in $8 \%$ eyes. The other causes of visual loss following PRP was vitreous haemorrhage (6\%), tractional retinal detachment (3\%), pre retinal haemorrhage (21\%) and cataract (2\%). In a study by Richard Kaiser et al showed vitreous haemorrhage developed in $37 \%$ of eyes during the first year after panretinal photocoagulation and tractional retinal detachment developed in $6 \%$ of eyes at 1 year follow up. In a study by James F. Vander et al showed that 6 of 59 eyes had vitreous haemorrhage following PRP for diabetic retinopathy. Other causes of visual acuity showed diabetic maculopathy and cataract were other causes of subnormal visual acuity.

\section{CONCLUSIONS}

PRP in high risk PDR reduces the risk of severe visual loss by more than $50 \%$. In our study PRP has shown to induce regression of neovascularization and arrest of progression of diabetic retinopathy. Also, laser treatment is preferable to no treatment, but a timely applied treatment is more affective as far as visual prognosis is concerned. In our study, $74.3 \%$ retained their baseline vision and decreased vision was noted in $22 \%$ of patients. Laser treatment, if carried out properly rarely causes serious complications. Some of the complications encountered were vitreous haemorrhage, preretinal haemorrhage, macular oedema, choroidal effusion, tractional retinal detachment and epiretinal membrane. In order to prevent the development of diabetic lesions in the eye, it is necessary to carry out regular ophthalmic checkups, to qualify patients to laser treatment as early as possible.

\section{REFERENCES}

[1] Snyers B. Proliferative diabetic retinopathy: laser photocoagulation treatment. Bull Soc Belge Ophthalmol 1995;256:87-94.

[2] The Diabetic Retinopathy Study Diabetic Research Group. Photocoagulation treatment of proliferative diabetic retinopathy. Clinical application of Diabetic Retinopathy Study (DRS) findings, DRS Report No. 8. Ophthalmology 1981;88(7):583-600.

[3] Blankenship GW. Fifteen-year argon laser and xenon photocoagulation results of Bascom Palmer Eye Institute's patients participating in the diabetic retinopathy study. Ophthalmology 1991;98(2):125-8.

[4] Vander JF, Duker JS, Benson WE, et al. Long-term stability and visual outcome after favourable initial response of proliferative diabetic retinopathy to panretinal photocoagulation. Ophthalmology 1991;98(10):1575-9.

[5] McDonald HR, Schatz H. Visual loss following panretinal photocoagulation for proliferative diabetic retinopathy. 
American Academy of Ophthalmology 1985;92(3):38893.

[6] Bowling B. Kanski's Clinical ophthalmology: a systematic approach. $8^{\text {th }}$ edn. Elsevier Publication 2016: p. 522.

[7] Dogru M, Nakamura M, Inoue M, et al. Long term visual outcome in proliferative diabetic retinopathy after panretinal photocoagulation. Japanese Journal of Opthalmology 1999;43(3):217-24.

[8] Qian Z, Zhu L, Zhao C. Observation on clinical effects of panretinal coagulation for diabetic retinopathy. Yan Ke Xue Bao 2002;18(2):99-101.
[9] Kaiser R, Maguire MG, Grunwald JE, et al. One-year outcomes of pan retinal photocoagulation in proliferative diabetic retinopathy. American Journal of Ophthalmology 2000;129(2)178-85.

[10] Rema M, Sujatha P, Pradeepa R. Visual outcomes of panretinal photocoagulatgion in diabetic retinopathy at oneyear follow up and associated risk factors. Indian Journal of 2005;53(2):93-9. 